Research Article

\title{
Experimental Study on Flexural Behaviour of Lightweight Multi-Ribbed Composite Slabs
}

\author{
Wei Huang $\left(\mathbb{D}\right.$, Xiang Ma $\mathbb{D}^{D}$, Bin Luo, Zeliang Li $\mathbb{D}^{\mathbb{D}}$, and Yujiao Sun \\ School of Civil Engineering, Xi'an University of Architecture and Technology, Xi'an, China \\ Correspondence should be addressed to Xiang Ma; maxi11@163.com
}

Received 4 July 2019; Accepted 30 August 2019; Published 13 October 2019

Academic Editor: Fabrizio Paolacci

Copyright (c) 2019 Wei Huang et al. This is an open access article distributed under the Creative Commons Attribution License, which permits unrestricted use, distribution, and reproduction in any medium, provided the original work is properly cited.

\begin{abstract}
To develop new slabs with light weight and high rigidity as well as meet the requirements of use and facilitate construction, a largespan multi-ribbed composite slab (R-CS) with filled lightweight blocks is proposed based on systematic research. Static tests of the bending behaviour of the four pieces of the R-CS specimens and one ordinary concrete cast-in-place slab were carried out. The fracture distribution, bearing capacity, deflection, and load-strain curves of the tensile steel bars were analysed. The difference in the bending behaviour between the R-CS specimens and the cast-in-place slab and the influence of different structural forms on the bending behaviour of the R-CS samples were studied. By calculating the bearing capacity of the fully composite state, their composite performance was evaluated. The research shows that the bending failure process of the R-CS specimens is similar to that of the cast-in-place slab and the crack and deflection development as well as ductility are relatively good. The measured bearing capacity of the specimen can reach more than $70 \%$ of the theoretical calculation strength under the fully composite state. The composite performance is satisfactory.
\end{abstract}

\section{Introduction}

The floor is one of the basic components of a building structure. Choosing a reasonable floor system can not only improve the mechanical properties of the whole structure but also reduce the cost, facilitate construction, and protect the environment. Due to repeated use of the floor structure, its cumulative mass accounts for $40 \%-60 \%$ of the total weight of the structure and the total weight of the structure is reduced by $5 \%$ for every $10 \%$ reduction in the floor weight [1]. The reduction of the floor self-weight also reduces the load of beams and columns and thus reduces the crosssectional size and reinforcement of the beams and columns. Moreover, a lighter structure indicates a smaller seismic response and further reduces the cross-sectional size and reinforcement of the beams and columns [2]. Assembled monolithic buildings have become the main form of assembled buildings because of their excellent overall performance. As an important component of the assembled monolithic concrete structure, the composite floor has good integrity, fast construction speed and reduced formwork, and it has been more widely used in engineering [3]. However, traditional solid prefabricated slabs are difficult to apply in large-span fields because more people, materials, and machines are needed for lifting and transportation due to the greater self-weight [4].

It has become an urgent problem to improve the structural performance of slabs, reduce costs, speed up construction, and develop a lightweight floor with a long span, which meets the use requirements and facilitates construction. According to the regional characteristics of the world and the advantages of local conventional floors, the development of prefabricated composite slabs to save formwork and speed up construction has become the choice of most researchers [5]. In 1936, American engineers attempted to fill inexpensive light wooden boxes in the middle of the beams and ribs of floors, which initiated the history of hollow floors. Hollow slab construction requires considerable internal formwork, and the corresponding positioning and antifloating process of internal formwork consumes a great deal of time. Additionally, construction quality control is difficult. Compared with other slabs, the 
advantages of hollow slabs are not obvious. A prefabricated hollow composite slab, with a bottom hollow prefabricated bottom slab and upper postpoured concrete, exhibits good cooperative performance between the prefabricated layer and cast-in-situ layer, but the cast-in-situ layer has a limited capacity to improve and the weight reduction effect of this component is not obvious [6-8]. Sandwich slabs and beamless floors with EPS and XPS as representatives have good thermal insulation performance and obvious weight reduction effects, but plastic is not environmentally friendly and the compatibility with concrete is poor $[9,10]$. The profiled sheeting-cement board and ferrocement composite board are recent development in the floor slab. Lightweight concrete was used as an infill material to act as a sound insulator for the floor. However, the limitations of this system are the high manufacturing and construction costs and its low stiffness which result in a large deflection and development of cracks in the finishing elements connected to the slab [11-13].

To overcome the problems of large self-weight, long construction period, excessive material consumption, and high cost in the construction of cast-in-situ floor systems or traditional assembled composite floors, an assembled lightweight multi-ribbed composite slab (R-CS) suitable for a large-span field is proposed based on our previous research in the assembled multi-ribbed composite structure system [14] (Figure 1). The slab (Figure 2) is mainly divided into a prefabricated composite layer and a cast-in-situ layer. The prefabricated layer is composed of a reinforced concrete base, half with embedded blocks. The other half of the block is exposed to form a prominent keyway. The cast floor can be used as a frame with good stiffness and a rough surface; the latter part finishes the rib pouring and then pours the top concrete, forming a composite slab, and the amount of castin-situ concrete is small.

The composite floor has the following advantages. The main advantage of this structure is the use of lightweight ecological blocks to replace core concrete that does not significantly improve the mechanical properties of the slab. First, the weight of the floor structure is greatly reduced by using lightweight ecological blocks to replace core concrete, without sacrificing the performance of the board, and the measured weight loss can reach approximately $30 \%$. Secondly, most of the blocks are processed from construction, industrial, and agricultural wastes. These blocks facilitate green environmental protection and contribute to the structural strength. For example, the filled aerated blocks studied in this paper are processed by materials such as industrial slag, which is light and has good strength. Additionally, aerated blocks exhibit superior performance, such as insulation and sound insulation, which further enhances the overall performance of the panels $[15,16]$. In addition, the slab incorporates industrial construction technology with simple construction processes and technical requirements, which are conducive to improving the production efficiency and is suitable for developing countries and regions with relatively backward technology and industrialization. Finally, by arranging the steel trusses in the longitudinal ribs in the slab, the superimposed

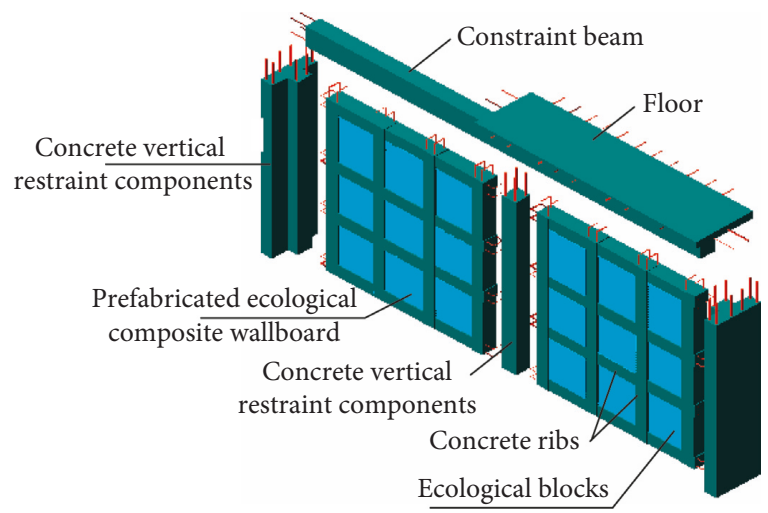

FIgURE 1: Fabricated composite wall.

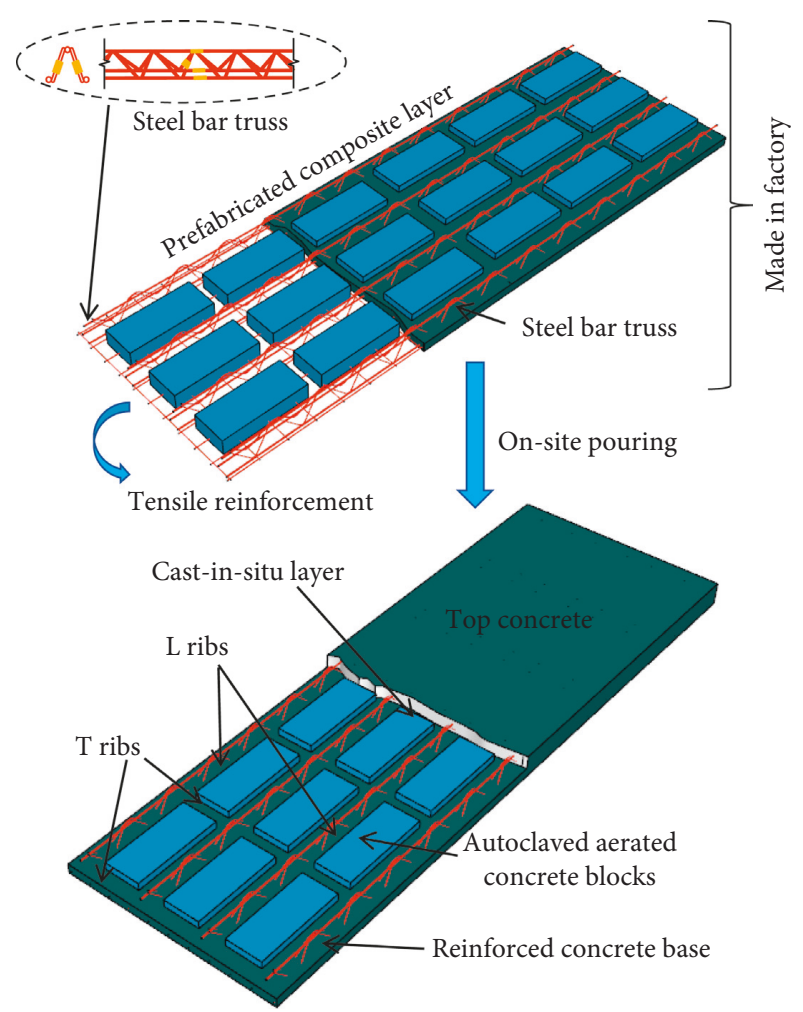

FIGURE 2: Fabricated lightweight multi-ribbed composite slabs.

performance and crack resistance of the test piece can be enhanced, the flexural bearing capacity can be significantly improved, and the applicable span range can also be increased [17].

In this paper, four full-scale bending behaviour tests of four R-CS (S1 S4) and one ordinary concrete cast-in-place slab (S6) are carried out. The failure characteristics, fracture distribution, bearing capacity, deflection, and load-tensile bar strain curve are analysed. The strain curve focuses on the influence of different structural forms, such as transverse ribs, longitudinal ribs, and top concrete, on the bending behaviour of the R-CS, and the composite properties of the test pieces are analysed and evaluated based on the test results and calculation. 


\section{Experimental Study}

2.1. Design and Fabrication of Specimens. Five specimens were tested in this batch, including one ordinary concrete cast-in-place slab (S6) and four R-CSs (S1 S4). The five specimens were $5700 \mathrm{~mm}$ long, $1440 \mathrm{~mm}$ wide, and $190 \mathrm{~mm}$ high. S1 S4 were cast twice, the precast composite bottom slab was poured for the first time, and the cast-in-place layer was poured after 28 days. The number of autoclaved aerated concrete blocks in S1, S2, S3, and S4 was 24, 32, 36, and 32, respectively. Among them, the size (length $\times$ width $\times$ height) of the S1 S3 aerated concrete blocks is $600 \times 240 \times 100$, and the size related to aerated concrete blocks of $\mathrm{S} 4$ is $600 \times 240 \times 140$. All R-CS longitudinal ribs are equipped with a steel truss. The diameter of the upper chord steel bar is $\varnothing 10$, the lower chord steel bar is $\varnothing 8$, and the web bar is $\varnothing 6$. The bottom concrete thickness $\left(h_{2}\right)$ of all slabs was $50 \mathrm{~mm}$, the top concrete thickness $\left(h_{1}\right)$ of S1, S2, and S3 was $40 \mathrm{~mm}$, and S4 had no top concrete. The cast-in-place S6 is cast in one time. 11 steel bars with a diameter of 12 are arranged at the bottom of the slab with a spacing of $140 \mathrm{~mm}$, and this configuration is the same as R-CSs'. The cast-in-place slab is not equipped with steel trusses. The details are shown in Figure 3 and Table 1 .

Specific manufacturing steps are divided into four steps: (1) placing reinforcement and pouring concrete; (2) placing aeration blocks, pouring longitudinal and transverse rib concrete to half the height of the rib, and curing to form a prefabricated composite layer; (3) placing the upper distributed steel bar; and (4) pouring the top concrete. The specific production process is shown in Figure 4.

2.2. Materials. The slab was poured with ordinary concrete, and the design strength grade was C30. The 28-day average cube strength $\left(f_{\text {cu.k }}\right)$ of this mix for the upper and lower layers was 27.7 and $32.3 \mathrm{~N} / \mathrm{mm}^{2}$, respectively. The corresponding elastic moduli are $2.91 E 4$ and $3.06 E 4 \mathrm{~N} / \mathrm{mm}^{2}$. The $150 \times 150 \times 150 \mathrm{~mm}$ cubes are used in this test, and the cubes and the specimens are poured in the same batch.

The density of aerated autoclaved concrete was $5.9 \mathrm{KN} / \mathrm{m}^{3}$, and the saturated compressive strength was $4.6 \mathrm{~N} / \mathrm{mm}^{2}$.

The test results of the properties of the steel bars are shown in Table 2:

2.3. Preparation and Load. To determine the behaviour of the composite slab under flexural conditions, the one-way slab was simply supported and two-line loads were adopted. Table 1 contains detailed information on the specifications and weight loss ratios. A hydraulic jack was used in the test. The loading system consisted of the gantry, a hydraulic jack, a load sensor, and 3 distribution beams. The force transfer of the jack was controlled by using a load sensor. The loading device is shown in Figure 5. The static loading process can be divided into preloading and formal loading stages. The preloading stage had three stages of loading and three stages of unloading; each stage was $2 \mathrm{kN}$. In the formal loading stage before cracking, each stage loading was $2 \mathrm{kN}$; after cracking, each stage loading was $4 \mathrm{kN}$. A 10 -minute waiting period was assumed prior to reading the values after each stage. In this way, the specimen could fully deform and crack, and then, the deflection was recorded and the strain data of steel and concrete were collected.

During the testing process, LVDTs were placed in the cast-in-place layer and the prefabricated layer at the end side of the slab to monitor the composite performance of the slab. LVDTs were also set at the midpoint and the third point of the specimens, and the strain gauges of steel and concrete were arranged at the key points of the specimens. The specific arrangement of the displacement gauge and strain gauge is shown in Figures 5 and 6, respectively.

When the specimen reached one of the following five marks, it was considered that the specimen had reached the ultimate state of bearing capacity and stopped loading: (1) the bending deflection reached 1/50 of the span; (2) the crack width at the main tendon of the tension reached $1.50 \mathrm{~mm}$ or the strain of the reinforcement reached 0.01 ; (3) the main tendon of the member was broken; (4) the concrete in the compression zone was cracked and broken; and (5) the overlapping surface failed [18].

\section{Results and Discussion}

The experimental data were analysed in the context of the crack distribution, bearing capacity, load-deflection profile, and load-strain curves of tensile steel bars.

3.1. Failure Characteristics and Fracture Distribution. The bending process of the five specimens is basically similar, and there are obvious elastic, elastic-plastic, and failure stages. The distribution of cracks at the bottom and side of the panels is shown in Figure 7, which shows the following:

(1) Compared with cast-in-situ slab S6, the crack development of the five R-CS specimens is basically similar. The main cracks are concentrated in the pure bending section between the two loading lines, showing a typical crack distribution characteristic of one-way slab bending failure.

(2) The fracture distribution and failure characteristics of the four R-CSs and a cast-in-place slab are compared and analysed as shown in Table 3.

3.2. Bearing Capacity. The measured values of the cracking load $P_{\mathrm{cr}}$, the yield load $P_{\mathrm{y}}$, and the ultimate load $P_{\mathrm{u}}$ of each specimen are shown in Table 4 . The results indicate the following:

(1) Comparison of the four R-CS specimens with castin-situ slab S6: because the four R-CS longitudinal ribs are equipped with a reinforcement truss, the ultimate bearing capacity of specimens S1 S4 increases by $47.5 \%, 39.4 \%, 36.4 \%$, and $37.6 \%$ compared with $\mathrm{S} 6$, while their weight decreases by $17.0 \%$, $22.6 \%, 25.4 \%$, and $31.6 \%$, respectively, indicating that truss reinforcement has an obvious effect on improving the bearing capacity of the specimens. 

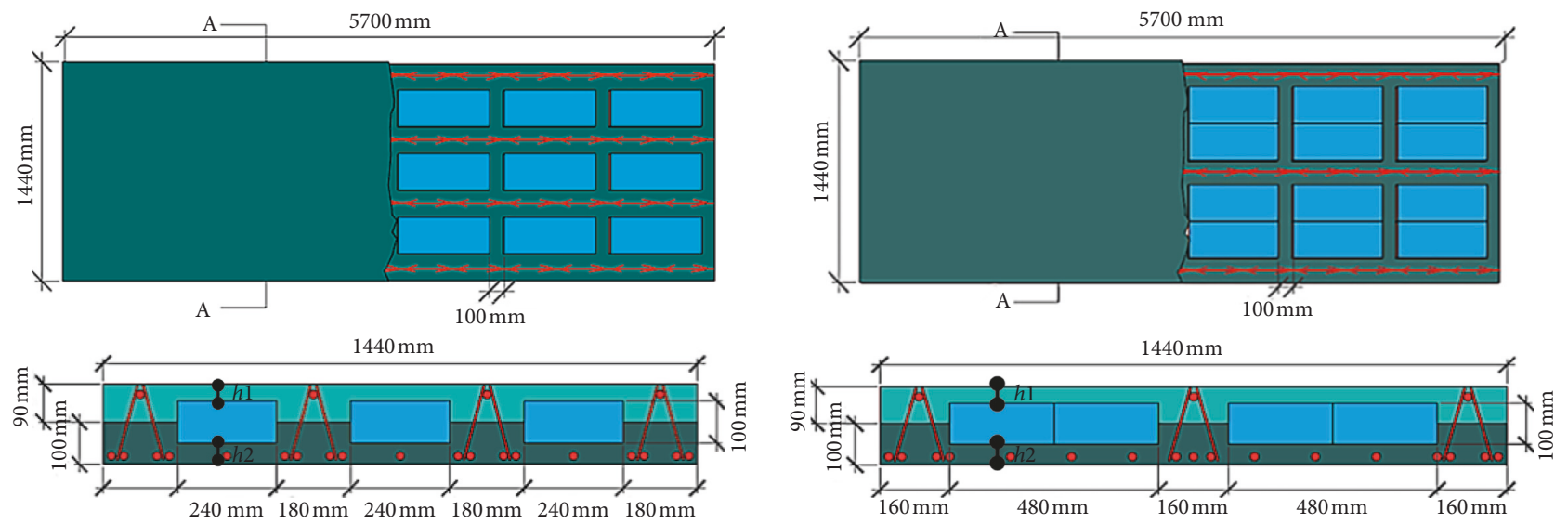

(a)

(b)
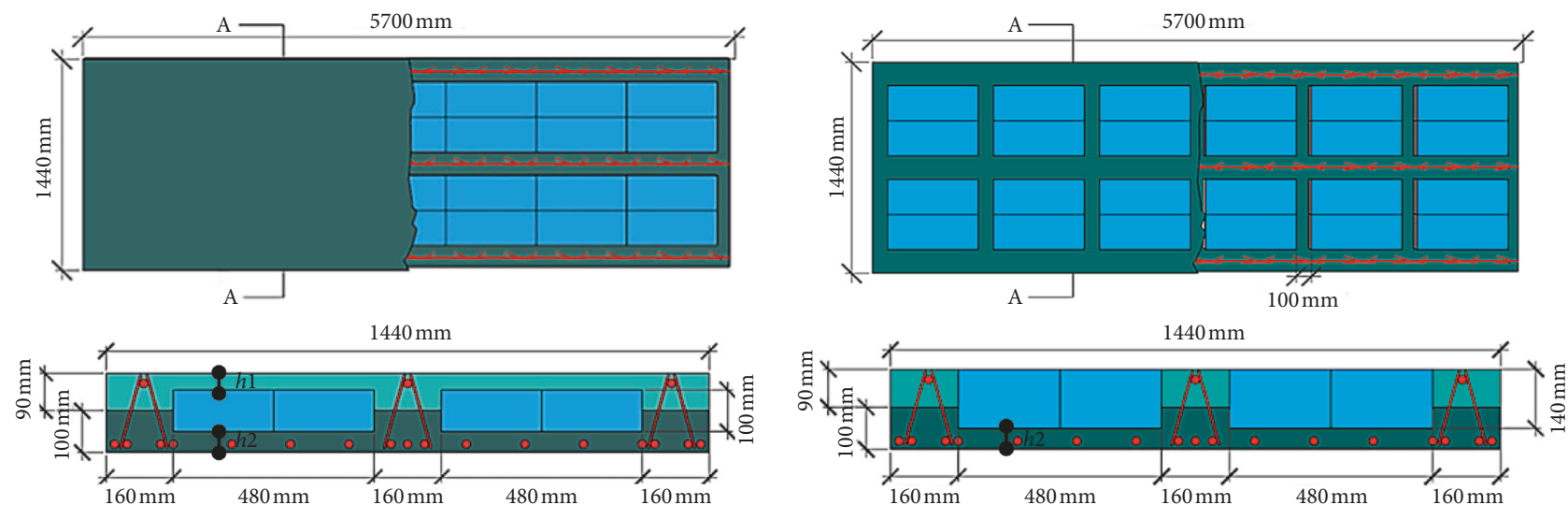

(c)

(d)

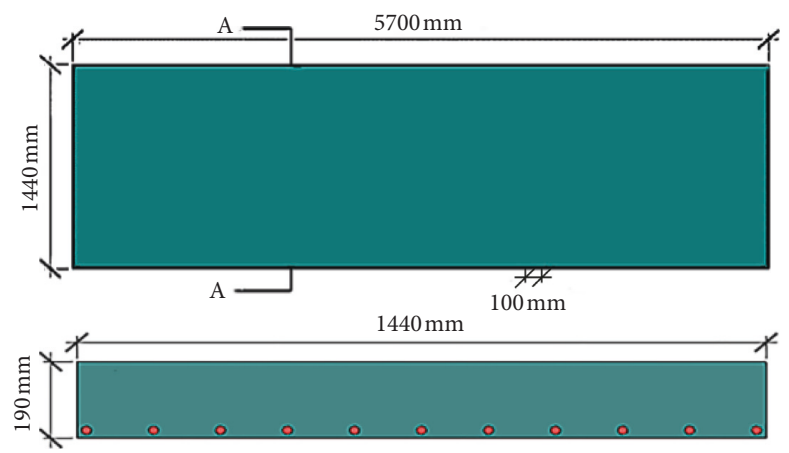

(e)

FIgURE 3: Brick layout and cross-sectional details of the specimens: (a) S1 brick layout and A-A cross-sectional details, (b) S2 brick layout and A-A cross-sectional details, (c) S3 brick layout and A-A cross-sectional details, (d) S4 brick layout and A-A cross-sectional details, and (e) S6 layout and A-A cross-sectional details.

TABle 1: Characteristics of all specimens.

\begin{tabular}{|c|c|c|c|c|c|c|c|}
\hline \multirow{2}{*}{ ID } & \multicolumn{3}{|c|}{ Self-weight (\%) } & \multirow{2}{*}{$\begin{array}{c}\text { Number of } \\
L^{\mathrm{a}} \text { ribs }\end{array}$} & \multirow{2}{*}{$\begin{array}{c}\text { Number of } \\
T^{\mathrm{b}} \text { ribs }\end{array}$} & \multirow{2}{*}{$h_{1}(\mathrm{~mm})$} & \multirow{2}{*}{$\begin{array}{c}\text { Reduction in weight } \\
\text { compared with } \\
\text { solid R. C\% }\end{array}$} \\
\hline & Precast & $\mathrm{AAC}$ & In situ & & & & \\
\hline S1 & 41.5 & 22.2 & 36.3 & 4 & 7 & 40 & 17.0 \\
\hline S2 & 37.8 & 29.6 & 32.6 & 3 & 7 & 40 & 22.6 \\
\hline S3 & 36 & 33.2 & 30.8 & 3 & 0 & 40 & 25.4 \\
\hline S4 & 31.9 & 41.4 & 26.7 & 3 & 7 & 0 & 31.6 \\
\hline S6 & 0 & 0 & 100 & 0 & 0 & - & 0 \\
\hline
\end{tabular}

Note. AAC: autoclaved aerated concrete blocks; $L^{\mathrm{a}}$ : longitudinal; $T^{\mathrm{b}}$ : transverse; $h_{1}$ : the top concrete thickness. 


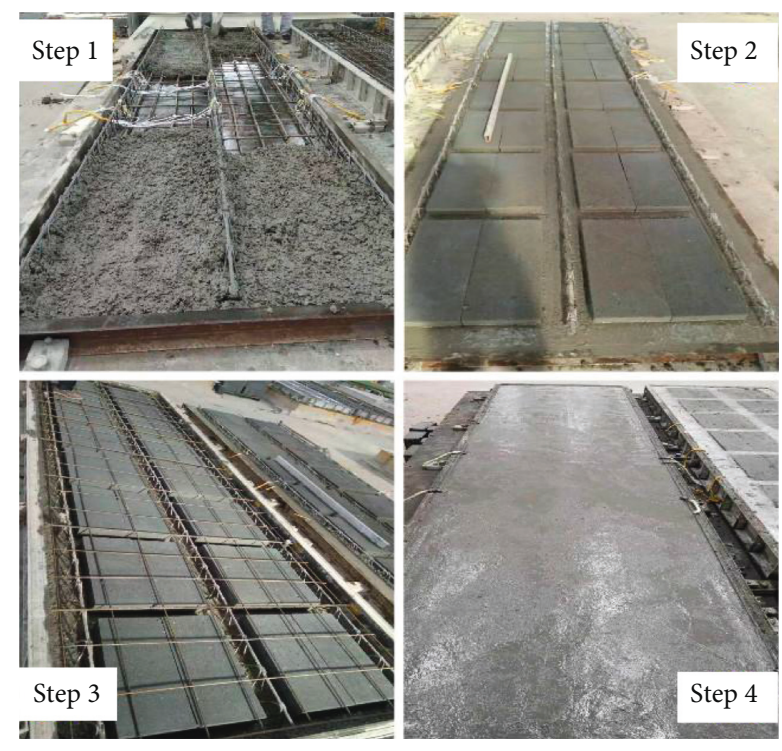

FIGURE 4: Stages of construction.

TABLE 2: Mechanical properties of the reinforcing bars.

\begin{tabular}{lccc}
\hline $\begin{array}{l}\text { Diameter } \\
(\mathrm{mm})\end{array}$ & $\begin{array}{c}\text { Yield strength } \\
f_{\mathrm{y}}(\mathrm{MPa})\end{array}$ & $\begin{array}{c}\text { Tensile strength } \\
f_{\mathrm{u}}(\mathrm{MPa})\end{array}$ & $\begin{array}{c}\text { Modulus of } \\
\text { elasticity } E_{\mathrm{s}}(\mathrm{MPa})\end{array}$ \\
\hline 8 & 400 & 496 & $1.95 \mathrm{E} 5$ \\
10 & 423 & 522 & $1.98 \mathrm{E} 5$ \\
12 & 402 & 492 & $1.96 \mathrm{E} 5$ \\
\hline
\end{tabular}

(2) Comparison of the four R-CS specimens: the longitudinal rib, transverse rib, and top concrete have little effect on the cracking load. The yield load and ultimate load of specimen S1 are increased by $12.96 \%$ and $5.75 \%$, respectively; the yield load and ultimate load of specimen S3 are decreased by $1.30 \%$ and $2.20 \%$, respectively; and the yield load and ultimate load of specimen S4 are decreased by $10.12 \%$ and $1.34 \%$, respectively, compared with S2. This finding shows that different structural forms have a certain influence on the yield load and ultimate load, and the order of influence is as follows: longitudinal rib $>$ top concrete $>$ transverse rib.

3.3. Load-Deflection Relation. The load-deflection curves of the five specimens are shown in Figure 8. The results are described as follows:

The curves of the five specimens during the loading process are basically the same, and they all go through three stages: elastic, elastic-plastic, and failure. The curve of the elastic stage basically shows a linear relationship. When concrete cracks into the elastic-plastic stage, the curve demonstrates the first obvious inflection point and the curve presents a climbing development. With the successive yielding of longitudinal reinforcement, the specimen enters the failure stage, the crack develops rapidly, and the deflection increases sharply.
Comparison of the four R-CS specimens with each other: Under the same load, the deflection of specimen S1 is the smallest, which shows that more longitudinal ribs can significantly improve the bending stiffness of the specimen. However, the curves of specimens S2 and S3 are similar, especially in the elastic stage; the curves basically coincide, which shows that setting transverse ribs has little effect on the bending stiffness of the specimen. The deflection of specimen S4 is the largest, and there is a small slip phenomenon during the later stage of loading. The concrete at the top of the slab has a great influence on the stiffness of the specimens. The specific displacement and ductility characteristics are shown in Table 5.

3.4. Load-Tensile Reinforcement Strain Relation. The loadtensile reinforcement strain curves of five specimens are compared in Figure 9. From Figure 9, it can be concluded that the curves are composed of a straight linear stage before concrete cracking, a climbing section after cracking to steel bar yielding, and a flat stage after steel bar yielding to the ultimate state of the bearing capacity of the specimens. The curves show good flexural failure characteristics, with the exception of the short elastic stage.

(1) Comparison of the four R-CS specimens with castin-place slab S6: the change trend of the 4 R-CS specimens and cast-in-place slab S6 is basically the same. Under the same load, the strain of the steel bars is less than that of specimen S6, which indicates that the steel truss in the longitudinal rib shares the tensile stress of the bottom longitudinal tension steel bars.

(2) Comparison of the four R-CS specimens with each other: Under the same load, the strain of the longitudinal tension steel bar at the bottom of specimen $\mathrm{S} 1$ is the smallest. Comparing S2 and S3, the strain of the tension bars at the bottom of the two specimens before steel yield is close. Only in the failure stage is the strain of the tension bars of specimen S3 slightly larger than that of specimen S2, which indicates that the transverse ribs have less influence on the stress of the tension bars. Comparing S2 and S4, the tensile strain of the steel bar at the bottom of specimen S4 is larger than that of S2 during the bending process, which indicates that the top concrete has an influence on the stress of the tension bars at the bottom of the specimens.

\section{Composite Performance Analysis and Evaluation}

4.1. Variation in the Strain along the Depth. The concrete strain distribution along the depth of the slab is shown in Figure 10 under various loads. As shown in Figure 10,

(1) Before the yielding of the steel bar, the strains of specimens S1, S2, and S3 have a good linear relationship along the slab height direction. As the load increases, the curve shows a certain bending. Before 


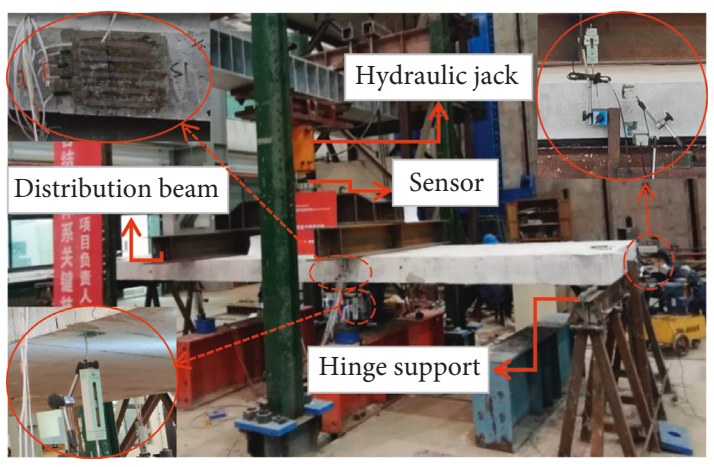

(a)

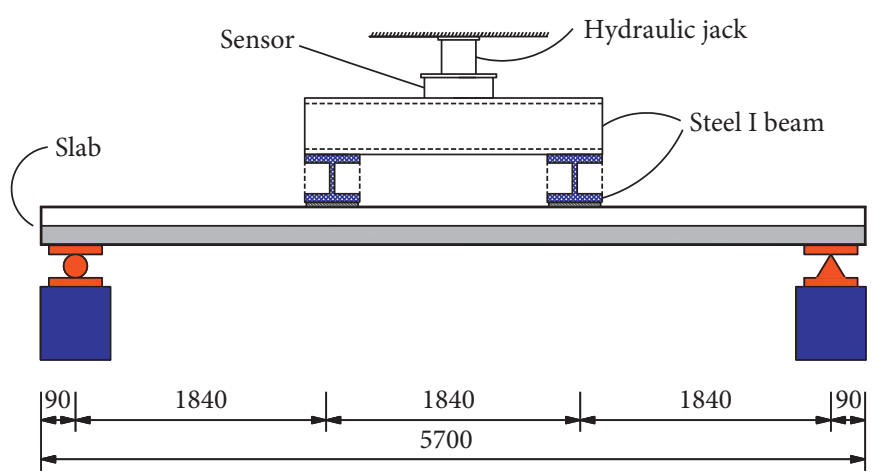

(b)

Figure 5: Loading test: (a) loading test site; (b) test setup.

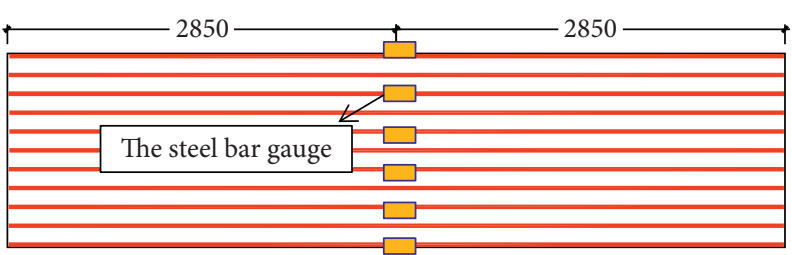

(a)

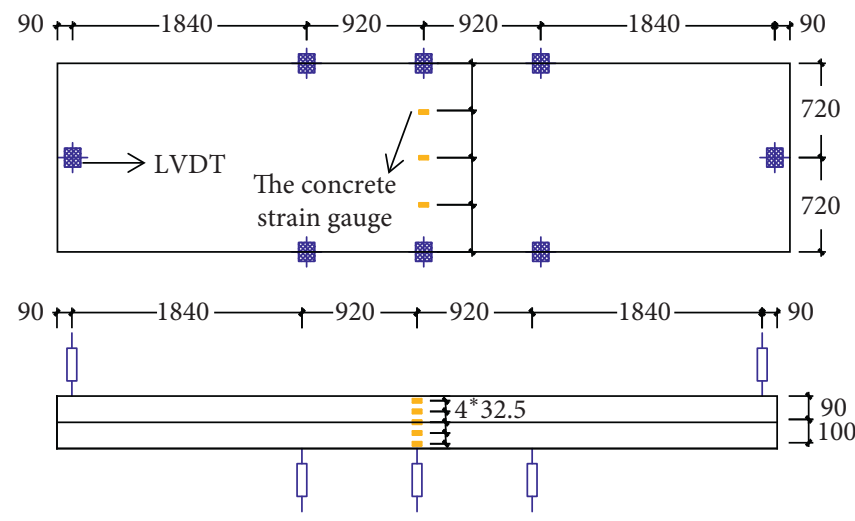

(b)

FIGURE 6: Locations of the strain gauges: (a) reinforced strain gauge arrangement; (b) concrete strain gauge arrangement.

the yield load is reached, the strain of the cross section of the specimen along the thickness of the slab has a good linear relationship, and the flat section assumption is true.

(2) Slab S4 shows similar changes with the other three pieces in the uncracked loading phase, and the crosssectional strain showed a linear relationship along the depth of the slab. When the load is increased to $35 \mathrm{kN}$ ( $50 \%$ of the yield load), the neutral axis position begins to move downward, indicating that the stacking layer begins to slip and the specimen then exhibits semicomposite bending behaviour.

4.2. Load-Slip Curve. The load (P)-slip $(\Delta)$ curve is measured by the LVDTs placed at the end of the prefabricated bottom layer and the cast-in-place layer. The results from Figure 11 are as follows:

(1) S1 compared with S2: the displacement curves of the upper and lower layers of the two composite specimens are all well-formed, and the amount of slip is small, which is basically negligible.

(2) S3 compared with S2: the slip amount of S3 is larger than that of $\mathrm{S} 2$, which means that at this size, the cross ribs need to be arranged for this type of slab to maintain good composite performance.

(3) S4 compared with S2: the slip amount of S4 is much larger than the slip amount of S2, and after reaching the yield load of 50\%, the upper and lower layers slip curves of S4 are separated, indicating that the test piece begins to slip, and this appears to be in phase with the neutral axis shifting phase in Figure 10(d). The relatively weak composite properties of S4 indicate that the top concrete has a greater impact on maintaining the work performance of the slab, which is greater than the effect of the transverse ribs.

4.3. Degree of Composite Action at the Elastic Stage. In the elastic stage, the composite properties of the specimens can be evaluated by $I_{\mathrm{e}} / I_{\mathrm{g}}[13]$, and the effective moment of inertia can be determined by the sectional stress according to the following formula:

$$
I_{\mathrm{e}}=\frac{M h}{\sigma_{\mathrm{b}}-\sigma_{\mathrm{t}}}
$$

where $\sigma_{\mathrm{b}}$ and $\sigma_{\mathrm{t}}$ are the stresses at the top and bottom of the slab, respectively; $M$ is the applied bending moment; and $h$ is the depth of the slab. 

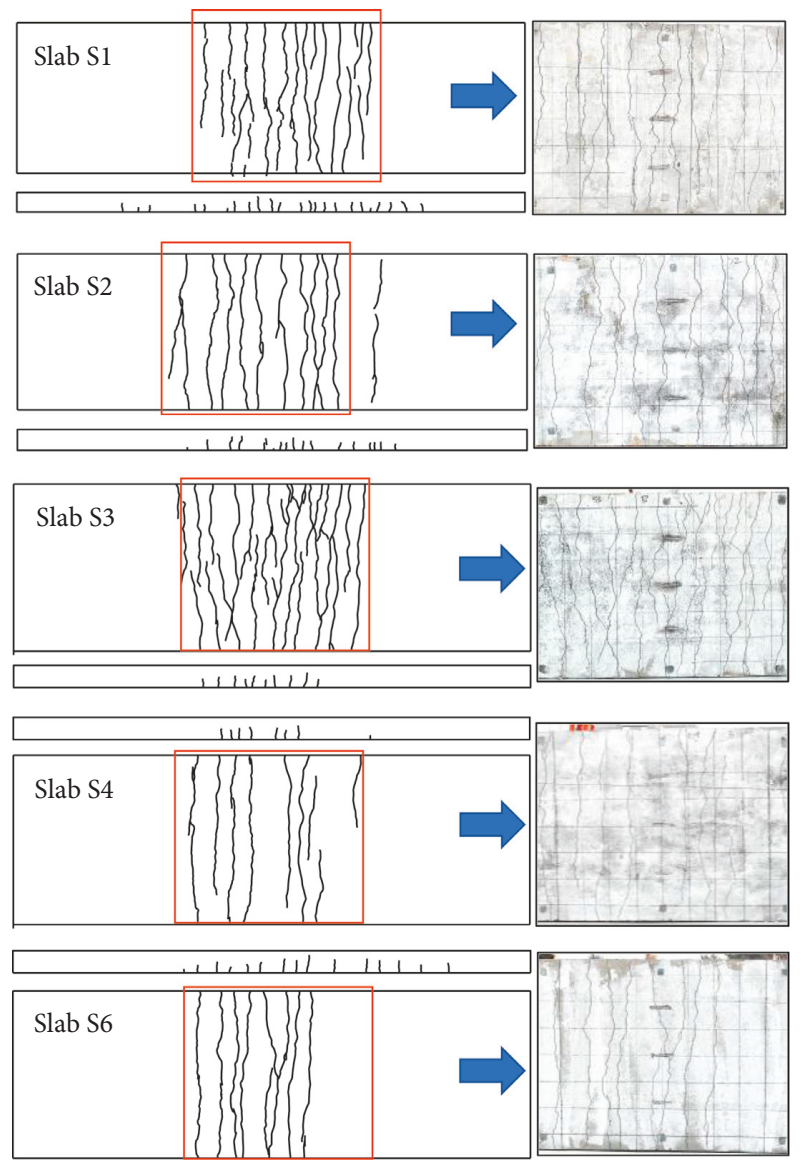

FIGURE 7: Images of the cracks.

TABle 3: Crack distribution and damage characteristics.

\begin{tabular}{|c|c|c|}
\hline ID & $\begin{array}{c}\text { Structural } \\
\text { characteristics }\end{array}$ & $\begin{array}{l}\text { Fracture distribution and } \\
\text { failure characteristics }\end{array}$ \\
\hline S1 & $\begin{array}{c}\text { More } \\
\text { longitudinal ribs }\end{array}$ & $\begin{array}{l}\text { The overall distribution of the cracks is } \\
\text { relatively uniform }\end{array}$ \\
\hline S2 & $\begin{array}{l}\text { Standard } \\
\text { specimens }\end{array}$ & $\begin{array}{l}\text { There are fewer regional cracks in the } \\
\text { transverse rib distribution area. }\end{array}$ \\
\hline S3 & No tr & $\begin{array}{l}\text { The } \mathrm{cr} \\
\text { texture } \mathrm{i}\end{array}$ \\
\hline S4 & No top & $\begin{array}{l}\text { The crack spacing is large, the width of a } \\
\text { single crack is the largest under the same } \\
\text { load, and there is no crushing } \\
\text { phenomenon of the aerated blocks }\end{array}$ \\
\hline S6 & Cast-in & The cracks ar \\
\hline
\end{tabular}

TABLE 4: Loading bearing capacity of the specimens.

\begin{tabular}{cccc}
\hline ID & $\begin{array}{c}\text { Cracking load } \\
P_{\mathrm{cr}}(\mathrm{kN})\end{array}$ & $\begin{array}{c}\text { Yield load } \\
P_{\mathrm{y}}(\mathrm{kN})\end{array}$ & $\begin{array}{c}\text { Ultimate load } \\
P_{\mathrm{u}}(\mathrm{kN})\end{array}$ \\
\hline S1 & 8.96 & 88.1 & 95.99 \\
S2 & 8.00 & 77.99 & 90.77 \\
S3 & 7.99 & 76.98 & 88.77 \\
S4 & 7.11 & 70.1 & 89.55 \\
S6 & 12 & 54.11 & 65.10 \\
\hline
\end{tabular}

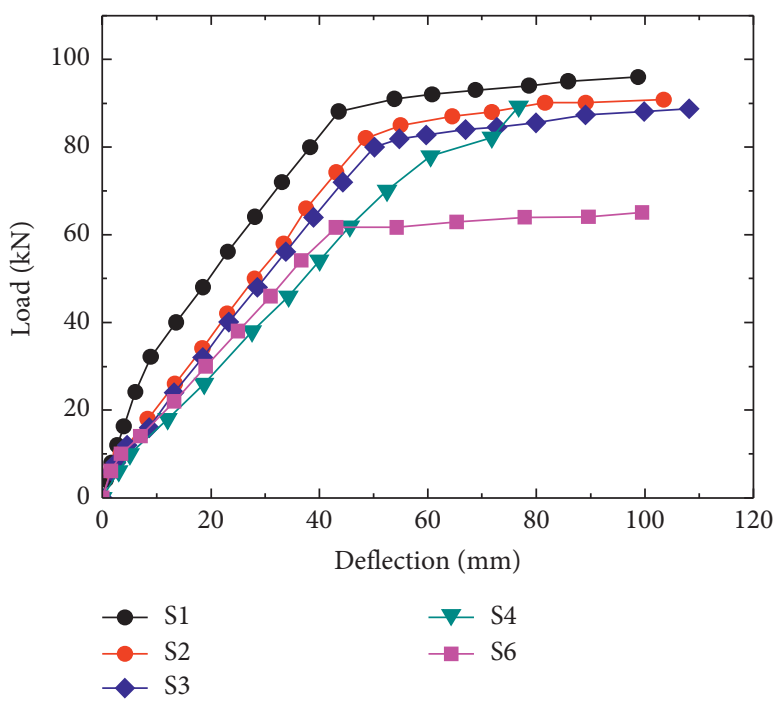

FIGURE 8: Load-displacement curves at midspan.

TABle 5: Deflection and ductility.

\begin{tabular}{lccc}
\hline ID & $\begin{array}{c}\text { Yield displacement } \\
f_{1}(\mathrm{~mm})\end{array}$ & $\begin{array}{c}\text { Limit displacement } \\
f_{2}(\mathrm{~mm})\end{array}$ & $\begin{array}{c}\text { Ductility } \\
\text { ratio }[19]\left(f_{2} / f_{1}\right)\end{array}$ \\
\hline S1 & 43.59 & 98.78 & 2.27 \\
S2 & 45.47 & 103.50 & 2.28 \\
S3 & 47.50 & 109.22 & 2.30 \\
S4 & 52.45 & 76.64 & 1.46 \\
S6 & 36.68 & 99.47 & 2.71 \\
\hline
\end{tabular}

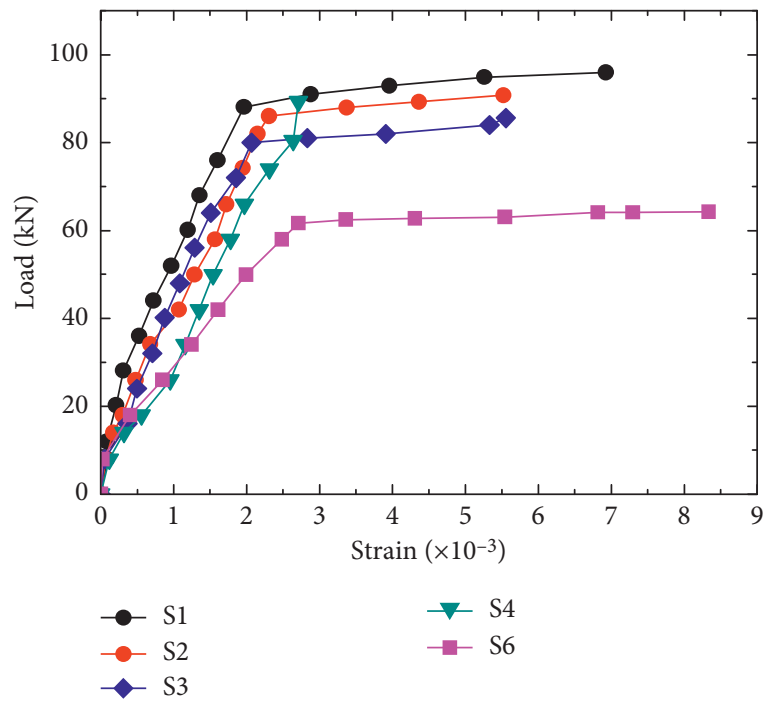

Figure 9: Load-strain curves of the tensile steel bars.

Table 6 gives the evaluations of the composite properties of the composite specimens at force $F=7 \mathrm{kN}, M=6.44 \mathrm{kN} \mathrm{m}$, and $h=190 \mathrm{~mm} . I_{\mathrm{g}}$ is the moment of inertia of the section under the fully composite state of the specimens, and S1 S4 do not consider the filler. The calculation diagrams of the slab are shown in Figure 12, and the corresponding calculation formulas are shown in Table 6. 


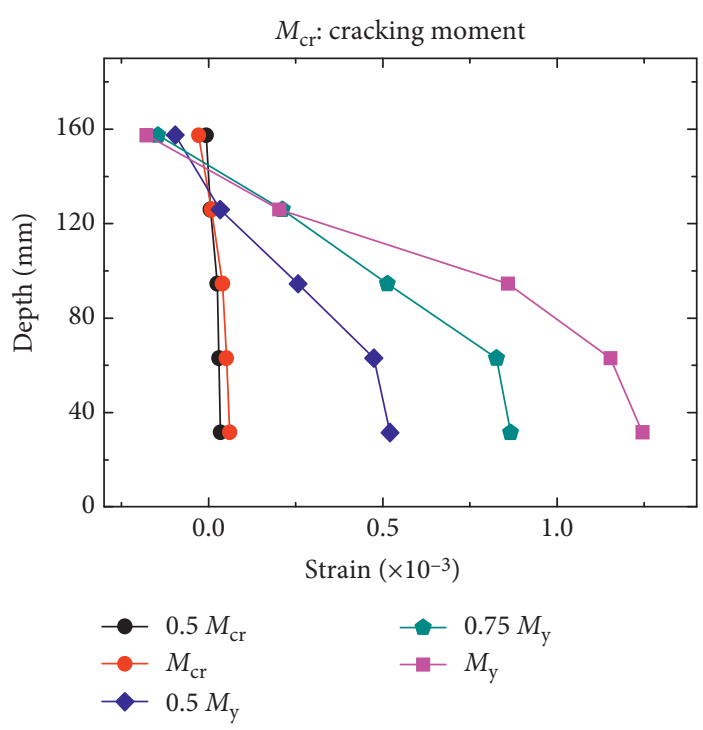

(a)

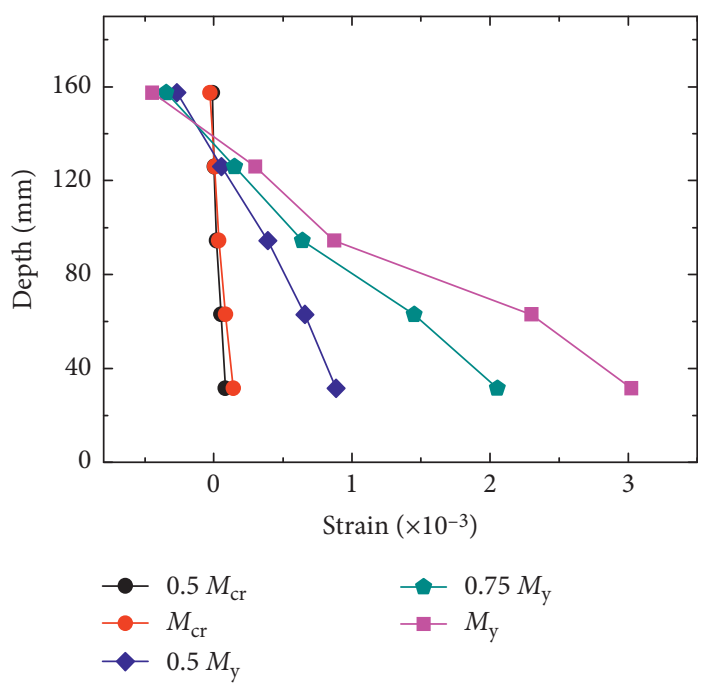

(c)

FIGURE 10: Variation in the strain along the depth:

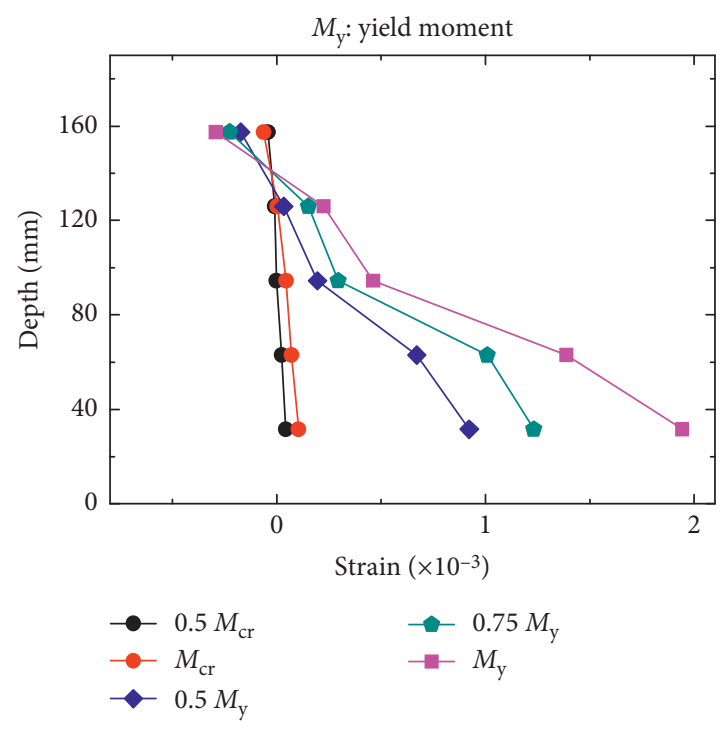

(b)

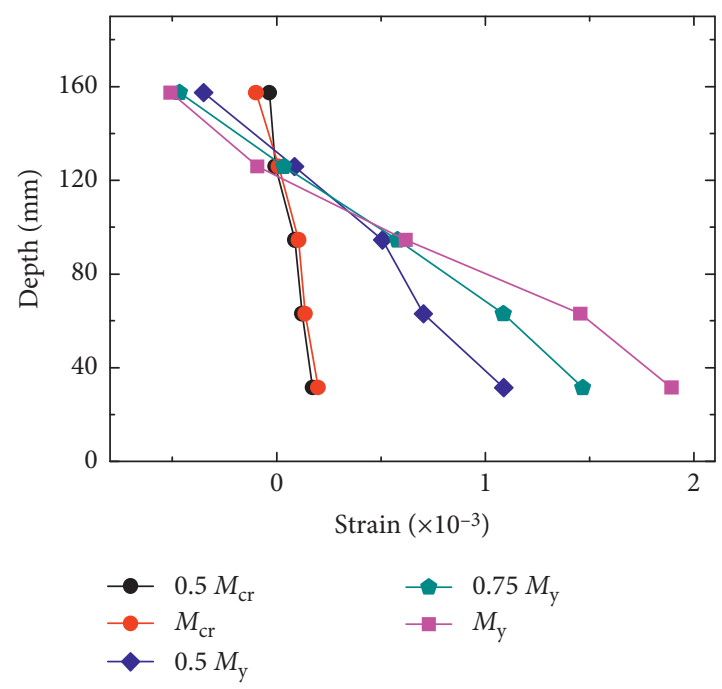

(d)
4.4. Analysis of Composite Performance in the Failure Stage. Because the composite performance and work performance are not easy to define, using the traditional method is difficult to accurately calculate the ultimate bearing capacity of the specimen. However, the bearing capacity of the limit states, i.e., fully composite state, can be calculated, and the composite performance of four composite specimens can be evaluated by comparing with the measured values.

When the panel is assumed to be fully composite at the ultimate strength (Figure 13(b)), the ultimate flexural capacity of the panel is calculated as shown in Table 7 [20].

Hence, the ultimate load carrying capacity of the slab per meter length $=8 \mathrm{M} / l^{2}$ and the slab span $l=5.52 \mathrm{~m}$.

The total load resisted by S1, S2, S3, and S4 as the full composite is $P_{\mathrm{u}}=142.03 \mathrm{kN}, 133.19 \mathrm{kN}, 133.19 \mathrm{kN}$, and $134.49 \mathrm{kN}$. Here, $f_{\mathrm{u}}$ is the compressive strength of concrete, $f_{\mathrm{c}}=0.76 f_{\text {cu.k }}[18], A_{\mathrm{s}}$ is the area of the tension reinforcement, $f_{\mathrm{u}}$ is the yield strength of the reinforcement, $b$ is the compression zone width, and $h_{0}$ is the depth of the reinforcement, as shown in Figure 13, $C$ is the compressive force in concrete, $M_{\mathrm{u}}$ is the ultimate moment capacity under flexure, $x$ is the depth of the neutral axis measured from the more highly compressed face, $T$ is the force in tension reinforcement and $\alpha$ is the coefficient of equivalent rectangular stress diagram of concrete compression zone.

As shown in Table 8, the actual bearing capacities of S1, S2, S3, and S4 are $27 \%, 26 \%, 28 \%$, and $28 \%$ less than those calculated by assuming a fully composite state, respectively. If we consider the percentage of composite action at ultimate strength to be the ratio of the theoretical ultimate strength assuming fully composite action to the ultimate strength obtained by test, then the slab S1 would be $73 \%$ composite, slab S2 is $74 \%$, slab S3 is $72 \%$, and slab S4 is $72 \%$ composite.

This result is slightly different from the evaluation of composite properties $(92 \%, 87 \%, 85 \%$, and $71 \%$ for slabs $S 1$, 


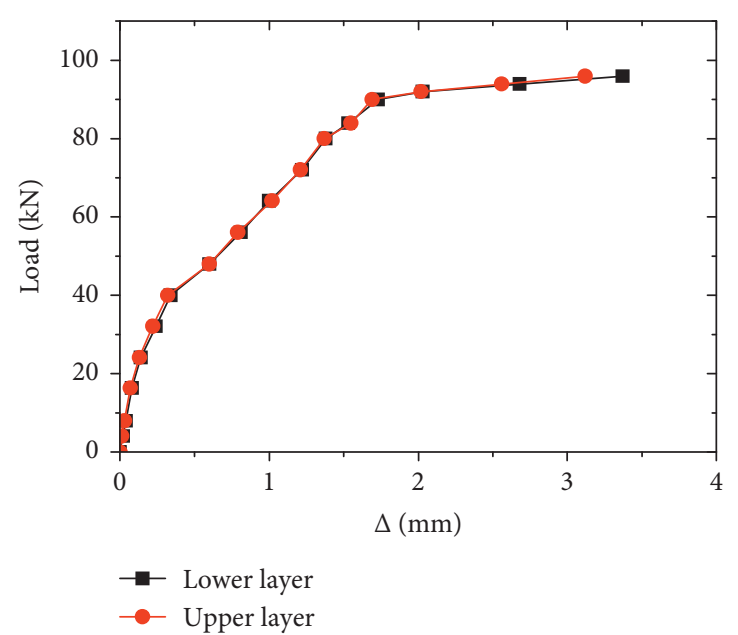

(a)

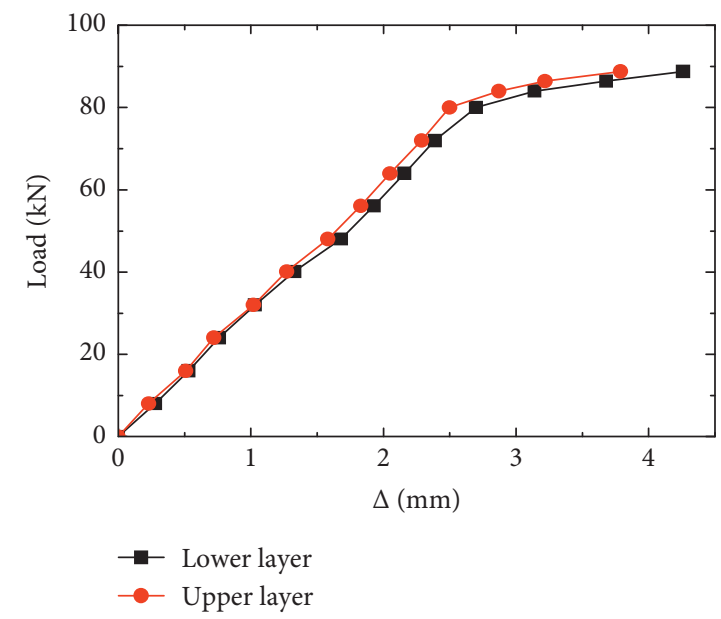

(c)

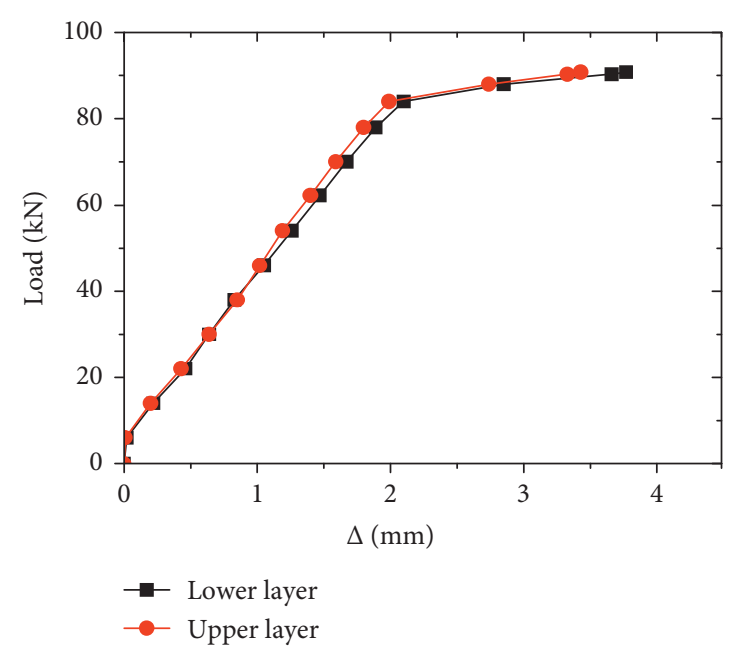

(b)

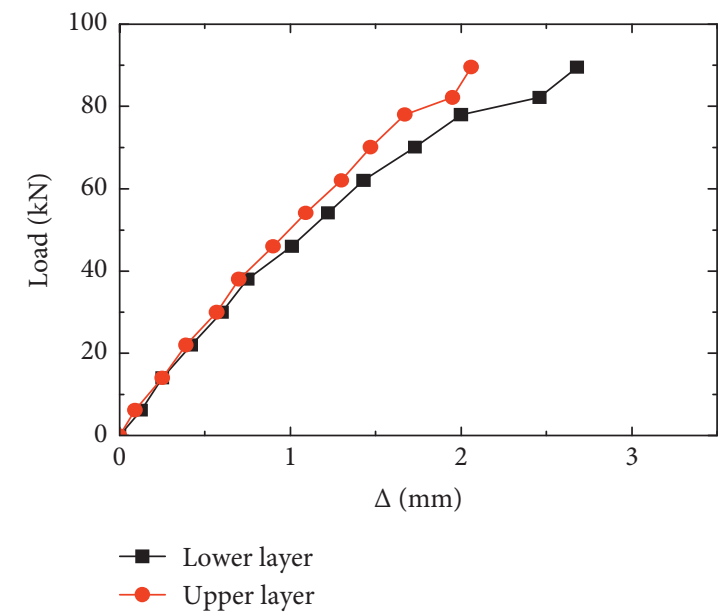

(d)

FIgUre 11: Load-slip curves of the slab end: (a) Slab S1; (b) Slab S2; (c) Slab S3; and (d) Slab S4.

TABLE 6: Amount of composite action.

\begin{tabular}{|c|c|c|c|c|c|}
\hline ID & $\sigma_{\mathrm{t}}\left(\mathrm{N} / \mathrm{mm}^{2}\right)$ & $\sigma_{\mathrm{b}}\left(\mathrm{N} / \mathrm{mm}^{2}\right)$ & $I_{\mathrm{e}}\left(10^{6} \mathrm{~mm}^{4}\right)$ & $I_{\mathrm{g}}\left(10^{6} \mathrm{~mm}^{4}\right)$ & $I_{\mathrm{e}} / I_{\mathrm{g}}$ \\
\hline S1 & -0.87 & 0.89 & 695.23 & 760.71 & 0.92 \\
\hline S2 & -0.76 & 1.16 & 637.29 & 739.37 & 0.87 \\
\hline S3 & -0.64 & 1.32 & 624.29 & 739.37 & 0.85 \\
\hline S4 & -1.25 & 2.72 & 307.13 & 430.44 & 0.71 \\
\hline
\end{tabular}

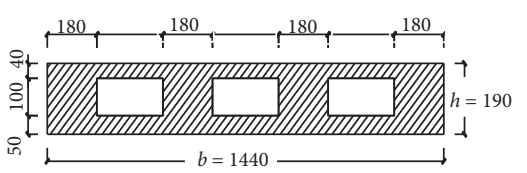

(a)

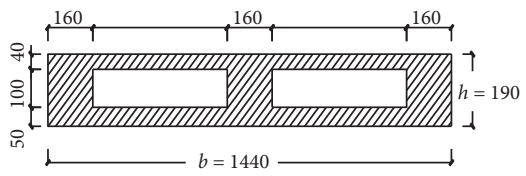

(b)

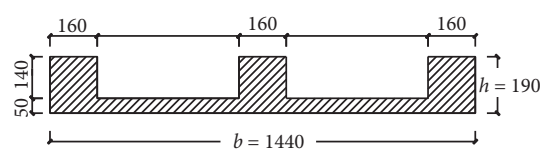

(c)

FIGURE 12: Sectional moment of inertia calculation diagram: (a) Slab S1; (b) Slabs S2 and S3; (c) Slab S4.

S2, S3, and S4, respectively) in Section 3.3 at the elastic stage. This difference is because under the influence of the aerated block, the stress distribution is caused by the shear lag phenomenon at the top, and the aerated block is deformed by extrusion, which makes the composite performance of the four test pieces different from the elastic stage. 

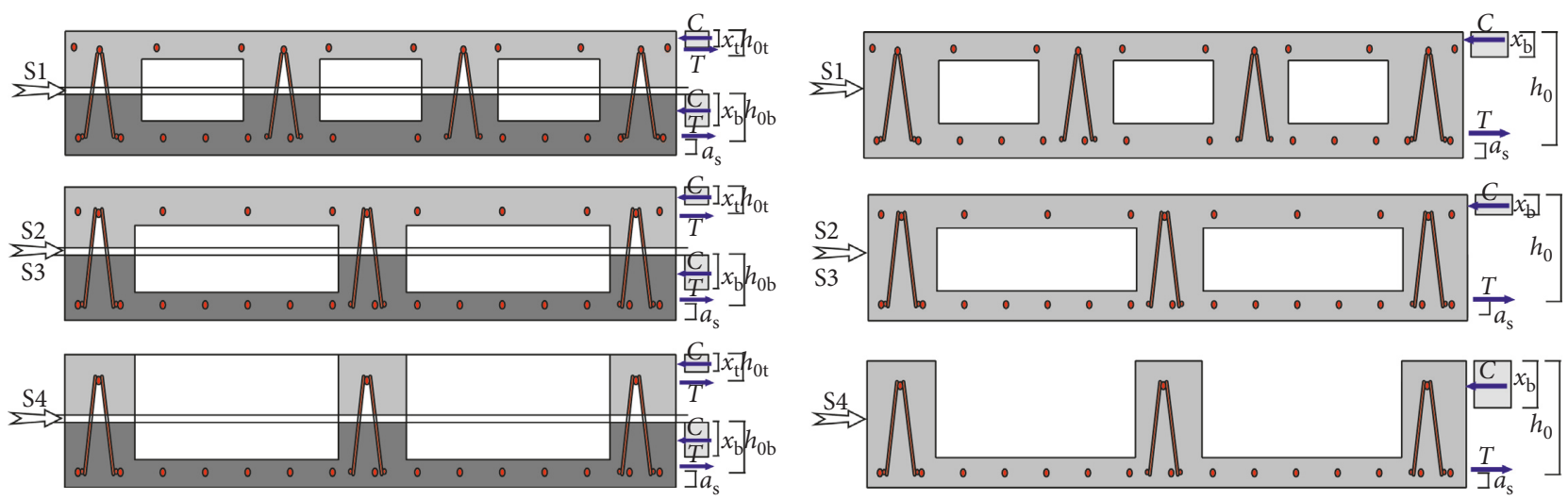

(a)

(b)

Figure 13: (a) Noncomposite state and (b) fully composite state.

TABLE 7: Ultimate moment of fully composite state.

\begin{tabular}{|c|c|c|c|}
\hline & S1 & S2 \& S3 & S4 \\
\hline Width of compression area $b$ & $1440 \mathrm{~mm}$ & $1440 \mathrm{~mm}$ & $480 \mathrm{~mm}$ \\
\hline $\begin{array}{l}\text { Equilibrium equation } C=\text { Tis used to define the depth } \\
\text { of neutral axis } x: \alpha f_{\mathrm{c}} b x+f_{\mathrm{y}}^{\prime} A_{\mathrm{s}}^{\prime}=f_{\mathrm{y}} A_{\mathrm{s}} \\
\text { The ultimate moment is then calculated using }\end{array}$ & $19.0 \mathrm{~mm}$ & $20.6 \mathrm{~mm}$ & $51.5 \mathrm{~mm}$ \\
\hline$M=\alpha f_{\mathrm{c}} b x\left(h_{0}-(x / 2)\right)+f_{\mathrm{y}}^{\prime} A_{\mathrm{s}}^{\prime}\left(h_{0}-a_{\mathrm{s}}\right)$ & $98.0 \mathrm{kN} \cdot \mathrm{m}$ & $91.9 \mathrm{kN} \cdot \mathrm{m}$ & $92.8 \mathrm{kN} \cdot \mathrm{m}$ \\
\hline
\end{tabular}

Table 8: Percentage of composite action at the ultimate load.

\begin{tabular}{lcc}
\hline ID & $\begin{array}{c}\text { Ultimate } \\
\text { strength }(\mathrm{kN})\end{array}$ & $\begin{array}{c}\text { Theoretical calculated ultimate } \\
\text { strength at } 100 \% \text { composite }(\mathrm{kN})\end{array}$ \\
\hline S1 & 103.69 & 142.03 \\
S2 & 98.47 & 133.19 \\
S3 & 96.47 & 133.19 \\
S4 & 97.25 & 134.49 \\
\hline
\end{tabular}

\section{Conclusion}

(1) The R-CS destruction process is similar to the typical failure process of ordinary one-way slab. From the beginning of loading to failure, the slab has experienced three stages: the elastic stage before cracking, the elastoplastic stage after cracking, and the failure stage after steel yielding. The development of cracks and deflections is relatively sufficient, and there is no sudden fracture or horizontal cracks along the superimposed surface.

(2) Compared with the cast-in-place slab S6, the R-CS specimens have a slightly lower cracking load, but the yield load- and the ultimate load-carrying capacity are higher. The displacement properties of the two specimens are good, and the displacement ductility coefficients are all approximately 2.5 .

(3) The longitudinal ribs of the built-in reinforced truss can effectively restrain the development of cracks, and the increase in the stiffness and ultimate bearing capacity of the slabs at all stages is significant. The top concrete has an obvious effect on improving the rigidity of the test piece and inhibiting the cracking of the bottom layer, but it does not affect the ultimate bearing capacity; the transverse ribs contribute to the stiffness and ultimate bearing capacity of the slab. The order of influence of the different structural forms on the yield load and ultimate load is as follows: longitudinal rib $>$ top concrete $>$ transverse rib.

(4) The bearing capacity of the composite slab is good, and the actual strength can reach more than $70 \%$ of the theoretical calculated strength in the fully composite state using GB50010-2010. Considering the large amount of light material blocks filled inside, the composite performance is satisfactory.

\section{Data Availability}

The data used to support the findings of this study are included within the article. 


\section{Conflicts of Interest}

The authors declare that there are no conflicts of interest.

\section{Acknowledgments}

This work was supported by the National Natural Science Foundation of China (grant nos. 51578446 and 51508021).

\section{References}

[1] Y. Yardim, A. M. T. Waleed, M. S. Jaafar, and S. Laseima, "AAC-concrete light weight precast composite floor slab," Construction and Building Materials, vol. 40, pp. 405-410, 2013.

[2] A. Gonzalez, E. Spacone, and R. Nascimbene, "Performancebased seismic design framework for RC floor diaphragms in dual systems," Procedia Engineering, vol. 199, pp. 3546-3551, 2017.

[3] A. A. Yee and P. H. D. Eng, "Social and environmental benefits of precast concrete technology," PCI Journal, vol. 46, no. 3, pp. 14-19, 2001.

[4] A. A. Yee, "Structural and economic benefits of precast/ prestressed concrete construction," PCI Journal, vol. 46, no. 4, 2001.

[5] S. Pessiki, R. Prior, R. Sause, and S. Slaughter, "Review of existing precast concrete gravity load floor framing systems," PCI Journal, vol. 40, no. 2, pp. 52-68, 1995.

[6] J. M. Barker, "Research, application, and experience with precast prestressed bridge deck panels," PCI Journal, vol. 20, no. $6,1975$.

[7] T. Ueda and B. Stitmannaithum, "Shear strength of precast prestressed hollow slabs with concrete topping," ACI Structural Journal, vol. 88, no. 4, pp. 402-410, 1991.

[8] E. Baran, "Effects of cast-in-place concrete topping on flexural response of precast concrete hollow-core slabs," Engineering Structures, vol. 98, pp. 109-117, 2015.

[9] J. D. R. Joseph, J. Prabakar, and P. Alagusundaramoorthy, "Precast concrete sandwich one-way slabs under flexural loading," Engineering Structures, vol. 138, pp. 447-457, 2017.

[10] D. Tomlinson and A. Fam, "Analytical approach to flexural response of partially composite insulated concrete sandwich walls used for cladding," Engineering Structures, vol. 122, pp. 251-266, 2016.

[11] E. Ahmed, W. H. Wan Badaruzzaman, and H. D. Wright, "Experimental and finite element study of profiled steel sheet dry board folded plate structures," Thin-Walled Structures, vol. 38, no. 2, pp. 125-143, 2000.

[12] W. H. W. Badaruzzaman, M. F. M. Zain, A. M. Akhand, and E. Ahmed, "Dry boards as load bearing element in the profiled steel sheet dry board floor panel system-structural performance and applications," Construction Building Materials, vol. 17, no. 4, pp. 289-297, 2003.

[13] A. Benayoune, A. A. A. Samad, D. N. Trikha, A. A. A. Ali, and S. H. M. Ellinna, "Flexural behaviour of pre-cast concrete sandwich composite panel - experimental and theoretical investigations," Construction and Building Materials, vol. 22, no. 4, pp. 580-592, 2008.

[14] W. Huang, M. Zhang, and Z. Yang, "A comparative study on seismic performance of precast shear walls designed with different variables," KSCE Journal of Civil Engineering, vol. 22, no. 12, pp. 4955-4963, 2018.

[15] E. Raue and E. Tartsch, "Experimental results of fatigue and sustained load tests on autoclaved aerated concrete," Journal of Civil Engineering and Management, vol. 11, no. 2, pp. 121-127, 2005.

[16] N. A. Memon, S. R. Sumadi, and M. Ramli, "Ferrocement encased lightweight aerated concrete: a novel approach to produce sandwich composite," Materials Letters, vol. 61, no. 19-20, pp. 4035-4038, 2007.

[17] W. Cao, J. Zhang, and H. Dong, "Experimental research on flexural performance of high strength recycled aggregate concrete slabs with steel bar truss," Journal of Building Engineering, vol. 35, no. 10, pp. 31-38, 2014.

[18] China Academy of Architectural Sciences, Standard for Test Methods of Concrete Structures, China Construction Industry Press, Beijing, China, 2012.

[19] F. Peng, Q. Hanlin, and Y. Lieping, "Discussion and definition on yield points of materials, members and structures," Engineering Mechanics, vol. 34, no. 3, pp. 36-46, 2017.

[20] China Academy of Architectural Sciences, GB50010-2010. Specification for Design of Concrete Structures, China Construction Industry Press, Beijing, China, 2010. 


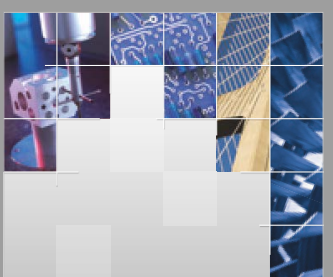

\section{Enfincering}
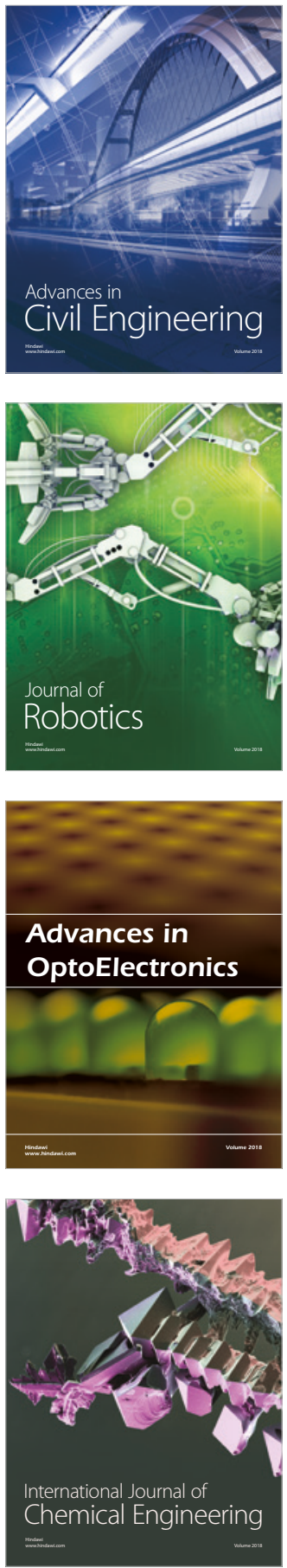

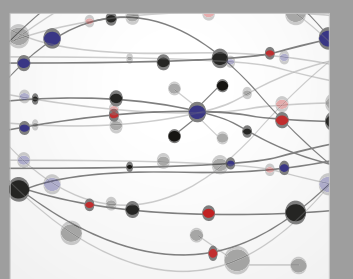

\section{Rotating \\ Machinery}

The Scientific World Journal

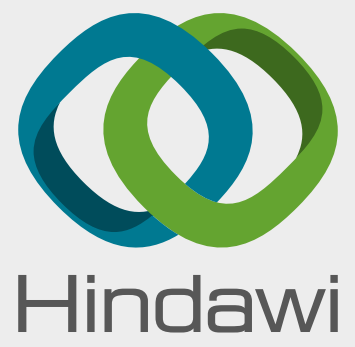

Submit your manuscripts at

www.hindawi.com
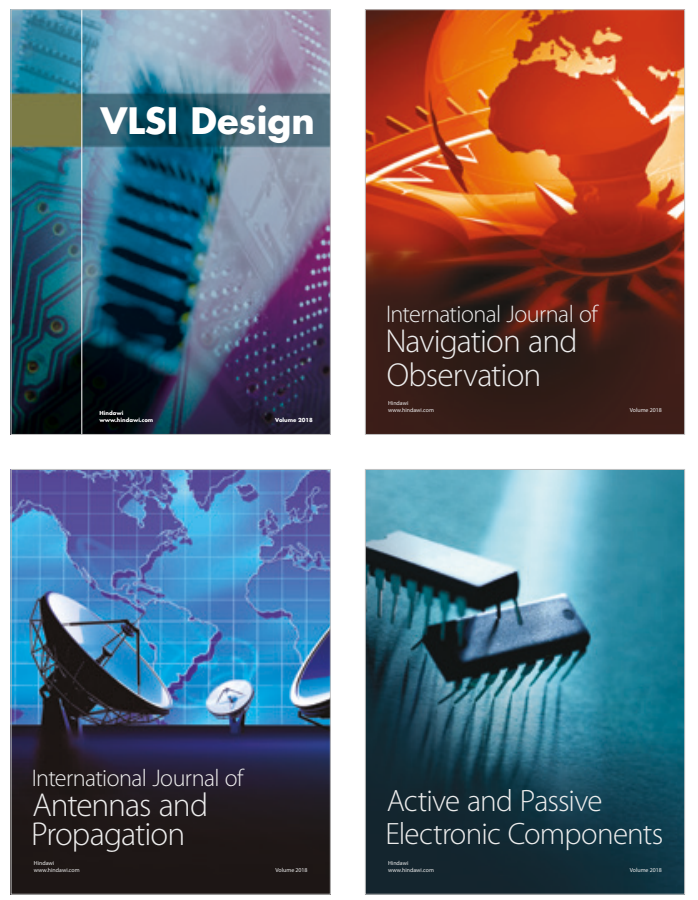
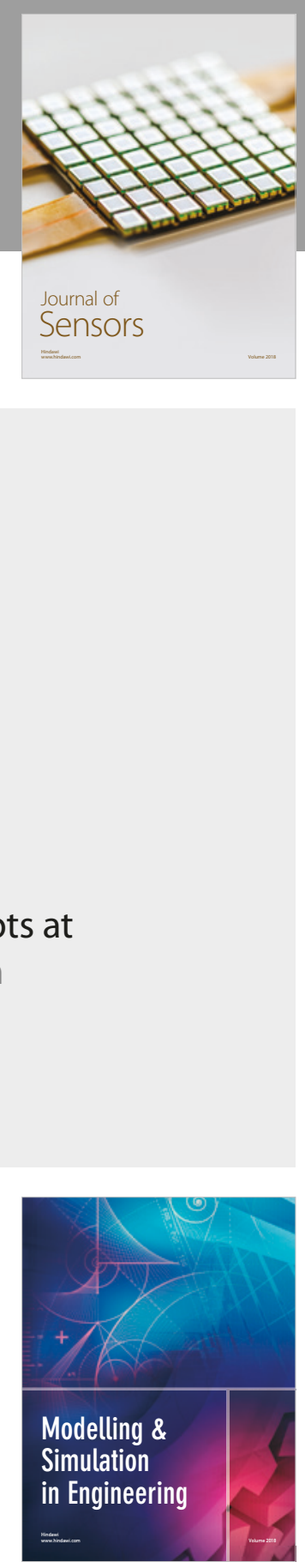

\section{Advances \\ Multimedia}
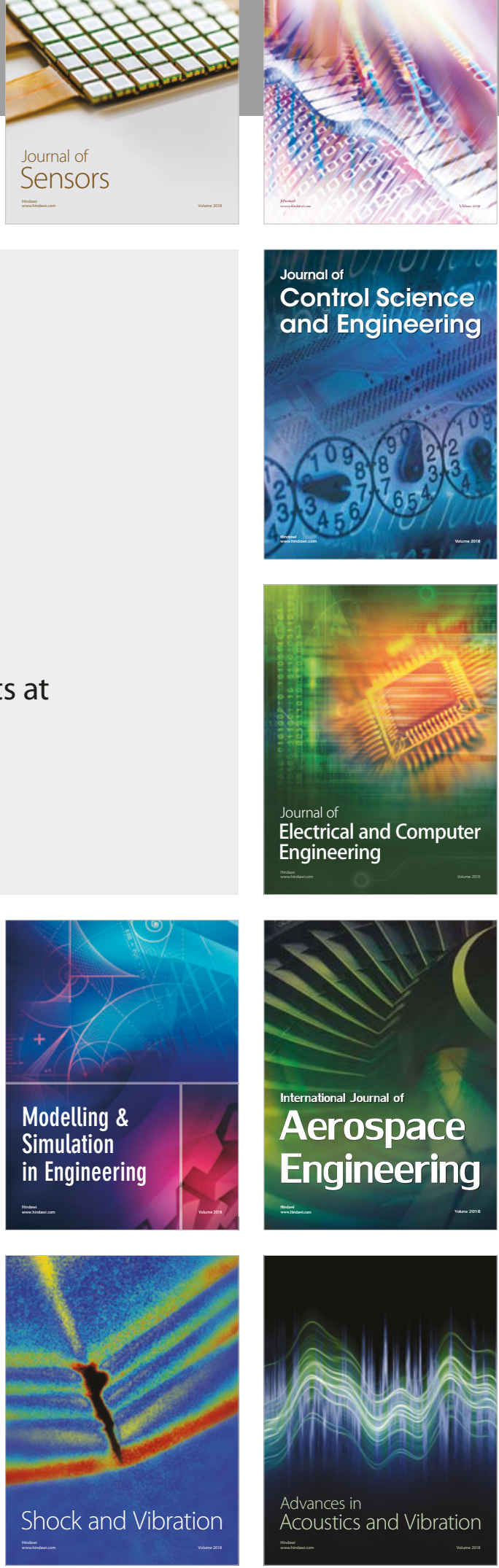